\title{
Fibroscan and Doppler Ultrasonography in the Assessment of Hepatocellular Carcinoma Interventional Therapy
}

\author{
Kariman Elkasrawy ${ }^{1, ~ *, ~ S a b r y ~ A b o u-s a i f ~}{ }^{1}$, Amr El-Badry ${ }^{2}$, Nehad Hawash $^{1}$, Mona Shehata ${ }^{1}$ \\ ${ }^{1}$ Tropical Medicine and Infectious Diseases Department, Faculty of Medicine, Tanta University, Tanta, Egypt \\ ${ }^{2}$ Radiodiagnosis Department, Faculty of Medicine, Tanta University, Tanta, Egypt \\ Email address: \\ kariman.elkasrawy@med.tanta.edu.eg (K. Elkasrawy), sabry.abousaif@med.tanta.edu.eg (S. Abousaif), \\ amr.elbadri@med.tanta.edu.eg(A. El-Badri),nehad.hawash@med.tanta.edu.eg (N. Hawash), mona.shehata@gmail.com (M. Shehata) \\ ${ }^{*}$ Corresponding author
}

\section{To cite this article:}

Kariman Elkasrawy, Sabry Abousaif, Amr El-Badry, Nehad Hawash, Mona Shehata. Fibroscan and Doppler Ultrasonography in the Assessment of Hepatocellular Carcinoma Interventional Therapy. International Journal of Medical Imaging. Vol. 9, No. 1, 2021 , pp. 36-44. doi: $10.11648 /$ j.ijmi.20210901.14

Received: December 31, 2020; Accepted: January 14, 2021; Published: January 22, 2021

\begin{abstract}
Background: studying hepatocellular carcinoma (HCC) interventional therapy by a simple, noninvasive techniquesthat doesn't require contrast material is valuable. Doppler ultrasound and fibroscanimaging gives anon-invasive demonstration of blood flow by real time observation and the fibrosis burden which can be related to HCC recurrence. Objectives: The aim of this study was to evaluate the role of fibroscan and Doppler ultrasonography in the assessment of efficacy and safety of hepatocellular carcinoma interventional therapy. Methods: this prospective study was conducted on HCC patients undergoing interventional therapy. The vasculature of both the liver and the focal lesion were assessed using Doppler ultrasonography and liver fibrosis burden was assessed usingfibroscan and compared to CT results. These tests were done one month before and 6 months after intervention. A cut off point of liver stiffness measurement (LSM) at which well ablation can be predicted was evaluated by receiver operating characteristic (ROC) curve. Results: Enrollment of 56 Egyptian patients was done. Portal hypertension (PHT) indices increased significantly after transarterial chemoembolization (TACE) and while did not after microwave ablation (MWA) indicating the safety of MWA. The vascularity of hepatocellular carcinoma point out areas of residual tumor. The TACE group showed high statistically significant increase in LSM after intervention $(\mathrm{P}<0.001)$. ROC curve analysis showed that LSM at cut off value $\leq 35.2 \mathrm{KPa}$ can predict good ablation of HCC with a sensitivity $78.38 \%$ and specificity $70.83 \%$. Conclusion: TACE is associated with increased portal hypertension indices than MWA and Doppler parameters is a non-invasive simple technique that can be used for follow up of HCC patients after interventional therapy. Also liver stiffness measurement can be used as a good predictor of good ablation of HCC.
\end{abstract}

Keywords: Hepatocellular Carcinoma, Doppler Ultrasonography, Liver Stiffness Measurement, Portal Hypertention, Fibroscan, Focal Lesion Vascularity

\section{Introduction}

Hepatocellular carcinoma (HCC) is estimated to be the sixth most common malignancy, the third leading cause of cancerrelated mortality worldwide and the fourth most common malignancy in Egypt [1, 2]. A background of chronic liver disease or cirrhosis is present in $70-90 \%$ of cases who develop HCC. So, various degrees of liver functional insufficiency are usually present at the time of cancer diagnosis. Surgical Resection is generally recommended for $\mathrm{HCC}$, but it is indicated only for patients with early is of liver fibrosis and well preserved liver function [3].

In spite of advances in screening, diagnosing, and treating $\mathrm{HCC}$, it is considered one of the most serious tumors due to its high rate of recurrence after treatment and its spread to other organs [4].

Although liver transplantation and surgical resection are considered to be the gold standard of HCC treatment, their invasive nature made them unsuitable for most of the HCC patients to which locoregional therapy is favourable due to its high safety and efficacy [5]. 
Irrespective of which locoregional treatment is performed, imaging plays a pivotal role in the follow-up of hepatic tumors, as it is the mean by which local treatment efficacy, recurrent disease, and therapy induced complications are evaluated [6].

Despite that computed tomography (CT) and magnetic resonance imaging (MRI) are still the most widely used imaging technique to describe the appearance of hepatic tumors treated with locoregional therapies, but both CT and MRI examinations require the use of contrast material which may limit their use in some situations. Therefore, the ability to detect residual viable tumor by a simple, noninvasive technique is valuable [6].

Doppler ultrasound (US) imaging gives an easy, noninvasive demonstration of blood flow by real time observation [7]. Also major advances in Doppler US technology increased its role in the assessment of the hemodynamics of hepatic focal lesions [8].

Necroinflammatory activity due to chronic hepatitis and fibrosis burden may lead to denovo carcinogenesis or multicenter occurrence of HCC in the liver " which can be related to HCC recurrence" therefore, quantification of liver fibrosis is important for predicting recurrence after applying HCC curative treatment [9].

While liver biopsy is still the gold standard for assessing liver fibrosis, the risk of complications and sampling errors limit its use [10].

An alternative for assessing liver stiffness (LS) is transient elastography which has been established as a useful noninvasive method for assessing the degree of liver fibrosis in patients with chronic liver disease [11].

The aim of this study was to evaluate the role of fibroscan and Doppler ultrasonography in the assessment of efficacy and safety of hepatocellular carcinoma interventional therapy.

\section{Materials and Methods}

\subsection{Patient Selection}

This prospective cohort study was conducted in Tanta University hospitals during the period from November 2017 to November 2019. Patients either attending to outpatient clinics or inpatients in Tropical Medicine and Infectious Diseases Department at Tanta University Hospitals who were diagnosed and proved to have HCC and were treated at the HCC intervention unit using either microwave ablation (MWA) or transarterial chemoembolization (TACE) according to a decision chosen by the multidisciplinary clinic were assessed for enrollment in our study.

Ethical committee approval was obtained from ethical committee of faculty of medicine, Tanta University approval code: 31752/09/17complying with the declaration of Helsenki. An informed written consent was taken from all included patients

Patients with Proven HCC by classical HCC criteria in triphasic CT, Child Turcotte Pugh (CTP) grade A or B were included in our study. While patients with CTP grade C, Patients with active variceal bleeding, presence of extra hepatic metastasis, Patients with portal vein thrombosis, Patients with platelet count less than 60,000 and/ or prothrombine activity less than $60 \%$ were excluded.

Fifty six (56) patients were enrolled in our study and all of them were subjected to: Full history taking and full clinical examination, laboratory investigations (complete blood count $(\mathrm{CBC})$, liver function tests, coagulation profile, blood urea, serum creatinine, alpha fetoprotein and hepatitis markers: HBsAg, anti $\mathrm{HBc}$ total For HBV, anti HCV antibody, quantitative PCR for HCV RNA).

Imaging evaluation

Patients have undergone radiological examination one week before intervention and were followed up 6 months after the intervention using;

Pelviabdominal Ultrasonography (US) to evaluate: Liver size and echogenicity, hepatic focal lesions as regard; number, size, location, echogenicity, capsulation, contact with the hepatic capsule or major hepatic vessels, Portal vein diameter and patency, common bile duct (CBD) dilatation, intrahepatic biliary radical dilatation (IHBRD), Splenomegaly, Ascites, or Enlarged abdominal lymph nodes.

Abdominal triphasic spiral C. T. scan or/ abdominal dynamic contrast MRI with magnetic strength $h \geq 1.5$ tesla was done to confirm U/S findings, and to study the pattern of enhancement of the focal lesions, the presence of satellites and vascular or biliary invasion and to follow up patients.

Doppler US: Doppler US of hepatic vessels and focal lesion arterial supply.

For evaluating and detecting: portal vein velocity (PVV), portal vein flow direction, hepatic artery resistance index (HARI), hepatic artery pulsatility index (HAPI), splenic artery resistance index (SARI), splenic artery pulsatility index (SAPI). Arterial vascularity of the focal lesion: resistance index and pulsatility index of the arterial supply of the lesion were calculated.

The following equations were calculated:

$$
\begin{gathered}
\text { Portal hypertension index }(\mathrm{PHI})=(\mathrm{HARI} \times 0.69) \times(\mathrm{SARI} \times \\
0.87) / \mathrm{PVV} .
\end{gathered}
$$

\section{Liver vascular index $(\mathrm{LVI})=\mathrm{PVV} / \mathrm{HAPI}$.}

All abdominal ultrasound and Doppler ultrasound were performed in in the Tropical Medicine Department using Toshiba Nemio XG apparatus (Toshiba, Japan) by a 3.5 MHz convex probe with B-mode and color Doppler ultrasound. Fasting for six hours at least before evaluation was asked to be done by the patients. During the evaluation, the patients were in the supine position. Doppler analysis was performed during quiet respiration or while the patients held their breath [12]. The Doppler gate was placed in the hilum of the spleen and in the portahepatis of the liver. The same observer usually unified the method for measuring each index to avoid interobserver variability and calculated the mean of 3 consecutive measurements.

Transient elastogram (Fibroscan): Liver stiffness measurement (LSM) by transient elastography was performed using a FibroScan502 (Echosens, Paris, France) 
with the M-probe or XL-probe. LSM was only performed by one experienced technician, who was blind to the patients' information. The results are expressed as kilopascals $(\mathrm{kPa})$. Ten valid measurements, at least $60 \%$ success rate and interquartile range (IQR) less than $30 \%$ were considered the median value of successful measurements was considered as a representative of the LSM value for a given patient.

Upper endoscopy: Was performed before therapeutic intervention and 6 months after intervention using Pentax EG-2985. Examination of the entire oesophagus, stomach, and proximal duodenum, wherever possible is doneby an experienced endoscopist.

\subsection{Statistical Analysis}

Statistical program for social science (SPSS) software version 22, 2015 USA was used to analyze data. Mean, standard deviation, median and range were used for description of quantitative variables. While frequency and percentages were used for qualitative variables. In order to compare a quantitative variable between two independent groups in parametric data Unpaired Student $t$ test and MannWhitney $U$ test were used. Chi square test was used to compare a qualitative variable between two independent groups. $\mathrm{P}$ value was significant if $\leq 0.05$. The area under the receiver operating characteristic (ROC) curve was calculated to measure the cutoff point that predict good ablation of HCC.

\section{Results}

From 108 patients examined to be included in this study 56 individuals were enrolled and we categorized them according to HCC ablative therapy they had receivedin 2 groups:

Group (I): Included 31 patients with HCC who had undergone TACE as a treatment modality of HCC.

Group (II): Included 25 patients with $\mathrm{HCC}$ who had undergone MWA as a treatment modality of $\mathrm{HCC}$.

Table 1. Doppler ultrasonography of hepatic focal lesion and its Comparison with triphasic CT for the sessment of the outcome of interventional therapy.

\begin{tabular}{|c|c|c|c|c|c|c|c|c|}
\hline \multirow{3}{*}{ FL vascularity } & \multirow{2}{*}{\multicolumn{2}{|c|}{ Total $(n=61)$}} & \multicolumn{4}{|c|}{ Intervention } & \multirow{3}{*}{$\chi^{2}$} & \multirow{3}{*}{$\mathbf{p}$} \\
\hline & & & \multicolumn{2}{|c|}{ TACE $(n=31)$} & \multicolumn{2}{|c|}{ MWA $(n=25)$} & & \\
\hline & No. & $\%$ & No. & $\%$ & No. & $\%$ & & \\
\hline \multicolumn{9}{|l|}{ Before intervention } \\
\hline Vascular & 52 & 93.4 & 30 & 96.8 & 22 & 88.0 & \multirow{2}{*}{1.606} & \multirow{2}{*}{${ }^{\mathrm{FE}} \mathrm{p}=0.314$} \\
\hline Avascular & 4 & 6.6 & 1 & 3.2 & 3 & 12.0 & & \\
\hline \multicolumn{9}{|l|}{ After intervention } \\
\hline Vascular & 26 & 42.6 & 16 & 51.6 & 10 & 40.0 & \multirow{2}{*}{0.750} & \multirow{2}{*}{0.386} \\
\hline $\mathrm{p}_{1}$ & \multicolumn{2}{|l|}{$<0.001^{*}$} & \multicolumn{2}{|c|}{$<0.001^{*}$} & \multicolumn{2}{|c|}{$<0.001^{*}$} & & \\
\hline FL RI & & & & & & & $\mathrm{U}$ & $\mathrm{p}$ \\
\hline Before intervention & \multicolumn{2}{|l|}{$(n=52)$} & \multicolumn{2}{|c|}{$(\mathrm{n}=30)$} & \multicolumn{2}{|c|}{$(n=22)$} & & \\
\hline Mean \pm SD & \multicolumn{2}{|l|}{$0.86 \pm 0.24$} & \multicolumn{2}{|c|}{$0.84 \pm 0.17$} & \multicolumn{2}{|c|}{$0.91 \pm 0.32$} & 316.0 & 0.795 \\
\hline After intervention & \multicolumn{2}{|l|}{$(n=26)$} & \multicolumn{2}{|c|}{$(n=15)$} & \multicolumn{2}{|c|}{$(\mathrm{n}=11)$} & & \\
\hline Mean \pm SD & \multicolumn{2}{|l|}{$0.95 \pm 0.18$} & \multicolumn{2}{|c|}{$0.95 \pm 0.20$} & \multicolumn{2}{|c|}{$0.96 \pm 0.15$} & 76.0 & 0.760 \\
\hline $\mathrm{p}_{1}$ & \multicolumn{2}{|l|}{$0.001^{*}$} & \multicolumn{2}{|c|}{$0.018^{*}$} & \multicolumn{2}{|c|}{$0.049^{*}$} & & \\
\hline Mean \pm SD & $1.62 \pm 0.58$ & & $1.65=$ & & 1.66 & & $=0.099$ & 0.921 \\
\hline After intervention & $(n=26)$ & & $(n=1$ & & $(n=1$ & & & \\
\hline Mean \pm SD & $1.80 \pm 0.40$ & & $1.82=$ & & 1.76 & & $\mathrm{t}=0.412$ & 0.684 \\
\hline $\mathrm{p}_{1}$ & 0.858 & & 0.655 & & 0.97 & & & \\
\hline & $\begin{array}{l}\text { CT after intervention } \\
\text { Well ablation }(n=32)\end{array}$ & & Resic & $(n=21)$ & New & sion $(n=3)$ & Test of Sig. & $\mathrm{p}$ \\
\hline Fl by Doppler After & & & & & & & & \\
\hline Vascular (n) & 6 & & 18 & & 2 & & $\chi^{2}=1.953$ & ${ }^{\mathrm{MC}} \mathrm{p}=1.000$ \\
\hline Avascular (n) & 26 & & 3 & & 1 & & & \\
\hline
\end{tabular}

$\mathrm{U}$ : Mann Whitney test $\mathrm{t}$ : Student t-test $\chi^{2}$ : Chi square test MC: Monte Carlo

$\mathrm{p}$ : $\mathrm{p}$ value for comparing between TACE and MWA

$\mathrm{p}_{1}$ : $\mathrm{p}$ value for Wilcoxon signed ranks test for comparing between before and after intervention

TACE: Transarterial chemoembolisation

RF: Radiofrequency ablation

MWA: Microwave ablation

FL: focal lesion

FLRI: focal lesion resistance index

FLPI: focal lesion pulsitality index

$\mathrm{p}$ : $\mathrm{p}$ value for association between different categories

*: Statistically significant at $\mathrm{p} \leq 0.05$

The mean age in group I was 62.13, while in group II was 58.72 , and no significant difference was recorded in studied groups $(\mathrm{P}=0.059)$.

As regard sex distribution males (37males) were more than females (19 females) in this study.

By using triphasic CT scan 32 patients' focal lesions showed well ablation results, 21 showed residual activity, and 3 patients had new focal lesions that were discovered on 
follow up. Out of the 32 well ablated lesions 26 lesions showed no vascularity on Doppler ultrasound examination and 18 lesions out of the 21 that had residual activity showed vascularity by Doppler ultrasound also 2 of the 3 newly developed lesions had vascularity that was detected by Doppler ultrasound examination. (Table 1)

Table 2. Liver vasculature indices and portal hypertention indices (portal hypertention index (PHTI) and liver vascular index (LVI)).

\begin{tabular}{|c|c|c|c|c|c|}
\hline & \multirow{2}{*}{ Total $(n=56)$} & \multicolumn{2}{|l|}{ Intervention } & \multirow{2}{*}{ Test of Sig. } & \multirow{2}{*}{$\mathbf{p}$} \\
\hline & & TACE $(n=31)$ & MWA $(n=25)$ & & \\
\hline \multicolumn{6}{|l|}{ HARI } \\
\hline Before & & & & \multirow{2}{*}{$\mathrm{t}=1.270$} & \multirow{2}{*}{0.209} \\
\hline Mean \pm SD & $0.78 \pm 0.12$ & $0.80 \pm 0.11$ & $0.76 \pm 0.12$ & & \\
\hline After & & & & \multirow{3}{*}{$\mathrm{t}=4.148^{*}$} & \multirow{3}{*}{$<0.001^{*}$} \\
\hline Mean \pm SD. & $0.84 \pm 0.15$ & $0.90 \pm 0.13$ & $0.76 \pm 0.13$ & & \\
\hline $\mathrm{P}_{1}$ & $<0.001^{*}$ & $<0.001^{*}$ & 1.000 & & \\
\hline \multicolumn{6}{|l|}{ HAPI } \\
\hline $\begin{array}{l}\text { Before intervention } \\
\text { Mean } \pm \text { SD. }\end{array}$ & $1.66 \pm 0.37$ & $1.71 \pm 0.36$ & $1.62 \pm 0.40$ & $\mathrm{t}=0.906$ & 0.369 \\
\hline After intervention & & & & \multirow{3}{*}{$\mathrm{t}=0.241$} & \multirow{3}{*}{0.810} \\
\hline Mean \pm SD & $1.78 \pm 0.39$ & $1.78 \pm 0.36$ & $1.81 \pm 0.44$ & & \\
\hline \multicolumn{4}{|l|}{ SARI } & & \\
\hline $\begin{array}{l}\text { Before intervention } \\
\text { Mean } \pm \text { SD. }\end{array}$ & $0.76 \pm 0.14$ & $0.77 \pm 0.13$ & $0.76 \pm 0.14$ & $\mathrm{t}=0.233$ & 0.817 \\
\hline After intervention & & & & \multirow[t]{3}{*}{$\mathrm{t}=2.208^{*}$} & \multirow[t]{3}{*}{$0.031^{*}$} \\
\hline Mean \pm SD & $0.79 \pm 0.15$ & $0.82 \pm 0.14$ & $0.74 \pm 0.14$ & & \\
\hline $\mathrm{p}_{1}$ & $0.019^{*}$ & $<0.001^{*}$ & 0.359 & & \\
\hline \multicolumn{6}{|l|}{ SAPI } \\
\hline $\begin{array}{l}\text { Before intervention } \\
\text { Mean } \pm \text { SD. }\end{array}$ & $1.49 \pm 0.37$ & $1.57 \pm 0.37$ & $1.41 \pm 0.37$ & $264.50^{*}$ & $0.043^{*}$ \\
\hline After intervention & & & & \multirow[t]{2}{*}{$175.0^{*}$} & \multirow[t]{2}{*}{$<0.001^{*}$} \\
\hline $\begin{array}{l}\text { Mean } \pm \text { SD } \\
\mathrm{p}_{1}\end{array}$ & $\begin{array}{l}1.55 \pm 0.43 \\
<0.001^{*}\end{array}$ & $\begin{array}{l}1.74 \pm 0.36 \\
<0.001^{*}\end{array}$ & $\begin{array}{l}1.35 \pm 0.42 \\
0.113\end{array}$ & & \\
\hline \multicolumn{6}{|l|}{ PVV } \\
\hline $\begin{array}{l}\text { Before intervention } \\
\text { Mean } \pm \text { SD. }\end{array}$ & $11.19 \pm 2.60$ & $11.07 \pm 2.35$ & $11.16 \pm 2.81$ & 365.50 & 0.717 \\
\hline After intervention & & & & \multirow[t]{3}{*}{$259.0^{*}$} & \multirow[t]{3}{*}{$0.034^{*}$} \\
\hline Mean \pm SD & $11.27 \pm 3.03$ & $10.66 \pm 2.81$ & $12.11 \pm 3.14$ & & \\
\hline $\begin{array}{l}\mathrm{p}_{1} \\
\text { LVI }\end{array}$ & 0.709 & $0.019^{*}$ & $<0.001^{*}$ & & \\
\hline $\begin{array}{l}\text { Before intervention } \\
\text { Mean } \pm \text { SD. }\end{array}$ & $7.21 \pm 2.37$ & $7.13 \pm 2.44$ & $7.26 \pm 2.36$ & 349.0 & 0.526 \\
\hline After intervention & & & & & \\
\hline Mean \pm SD. & $6.81 \pm 2.34$ & $6.69 \pm 2.55$ & $6.97 \pm 2.14$ & 327.50 & 0.323 \\
\hline $\mathrm{p}_{1}$ & $0.002^{*}$ & $0.025^{*}$ & 0.300 & & \\
\hline PHT I & & & & & \\
\hline Before intervention & & & & $\mathrm{t}=0.441$ & 0.661 \\
\hline Mean \pm SD & $0.03 \pm 0.02$ & $0.03 \pm 0.01$ & $0.03 \pm 0.02$ & & 0.001 \\
\hline After intervention & & & & $\mathrm{t}=2.639^{*}$ & $0.011^{*}$ \\
\hline $\begin{array}{l}\text { Mean } \pm \text { SD. } \\
\mathrm{p}_{1}\end{array}$ & $\begin{array}{l}0.04 \pm 0.02 \\
<0.001^{*}\end{array}$ & $\begin{array}{l}0.05 \pm 0.02 \\
<0.001^{*}\end{array}$ & $\begin{array}{l}0.03 \pm 0.02 \\
0.061\end{array}$ & & \\
\hline
\end{tabular}

$\mathrm{t}$ : Student t-testp: $\mathrm{p}$ value for comparing between TACE and MWA

$\mathrm{p}_{1}$ : $\mathrm{p}$ value for Wilcoxon signed ranks test for comparing between before and after intervention

TACE: Transarterial chemoembolization; RF: Radiofrequency ablation; MWA: Microwave ablation; HARIhepatic artery resistance index; HAPI hepatic artery pulsitality index; SARI splenic artery resistance index; SAPI splenic artery pulsitality index; PVV: portal vein velocity; LVI: liver vascular index; PHTI: portal hypertension index.

*: Statistically significant at $\mathrm{p} \leq 0.05$

The results of parameters measured by color Doppler as regard the hepatic focal lesion vascularity before and after intervention in the two groups showed significant differences $(\mathrm{P}<0.001)$. As regard the resistance index of the focal lesion arterial supply we found a highly statistical significant increase after intervention with $6.50 \%$ change $(\mathrm{P}=0.018)$ in TACE group and $0.96 \%$ in MWA group with statistically significant increase $(7.02 \%)(\mathrm{P}=0.049)$. Regarding the pulsatility index showed no statistically significant change in the studied groups before and after intervention $(\mathrm{P}=0.655)$ in TACE group and (0.977) in MWA group. (Table 1, Figure 3)

In the MWA group, there were no statistically significant results concerning PHT parameters by Doppler ultrasound except for HAPI that was increased from the mean of $1.62 \pm 0.40$ to $1.81 \pm 0.44$ with a percent of change $\uparrow 12.35 \pm 16.01(\mathrm{P}=0.001)$ in $88 \%$ of patients. and portal vein velocity showed statistically significant increased values from mean value $11.16 \pm 2.81$ to $12.11 \pm 3.14$ with 
$\uparrow 8.52 \pm 6.35 \%(\mathrm{P}<0.001)$ in $96 \%$ of patients while decreased only in $4 \%$ of patients who had MWA as a treatment.

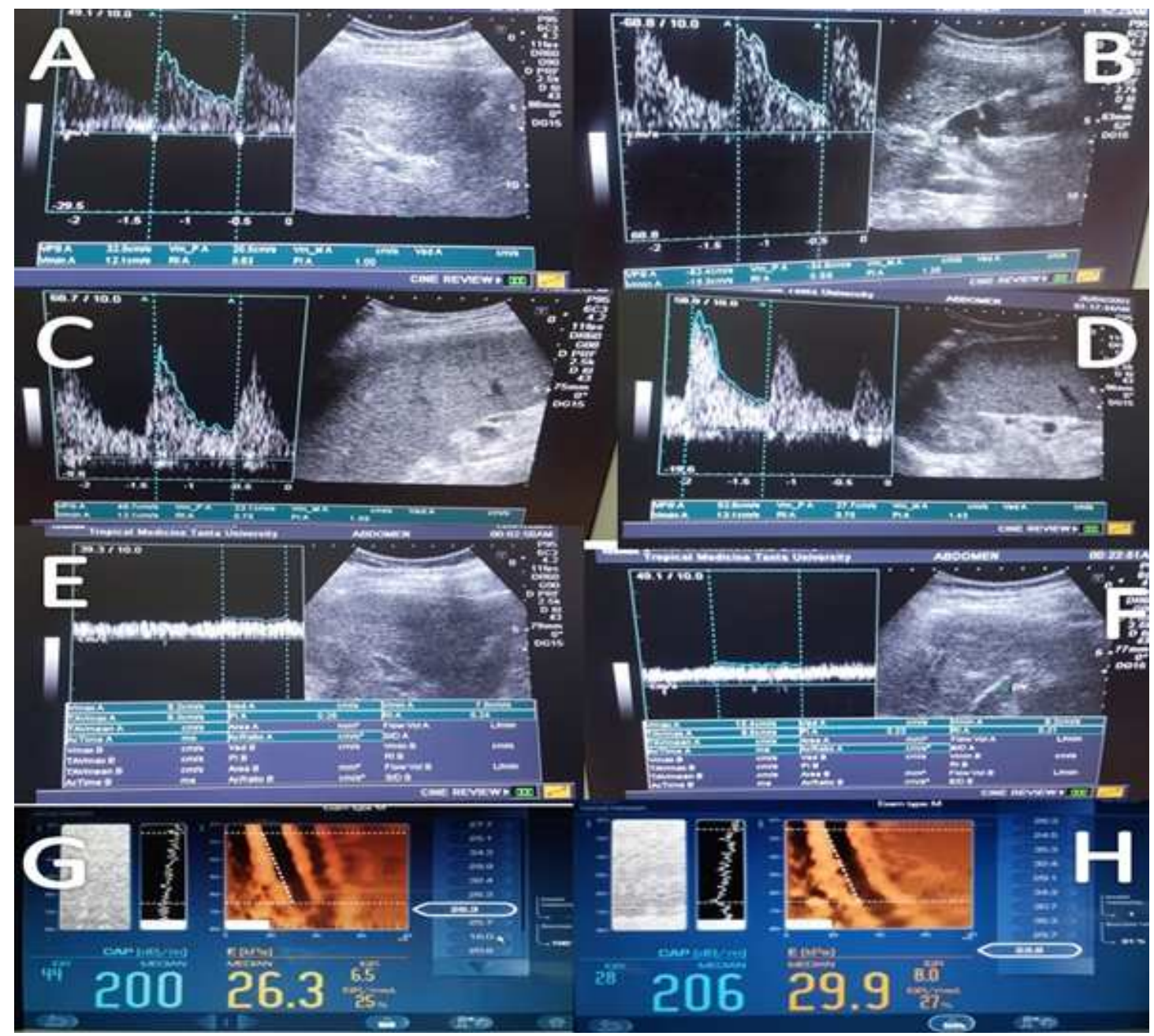

Figure 1. Hepatic artery resistance index, and pulsatility index before $(A)$ and after $(B)$ intervention, splenic artery resistance index, pulsitality index before $(C)$ and after $(D)$ intervention, portal vein velocity before $(E)$ and after $(F)$ intervention and liver stiffness measured by fibroscan before $(G)$ and after $(H)$ intervention in 46 years old patient who had MWA as an interventional therapy to HCC and follow up of CT after 6 months of therapy showed well ablation of the focal lesion.

In this work the studied TACE group showed marked increase in tissue resistances and PHT parameters after intervention as evidenced by the significant increase in HARI in $80.6 \%$ of patients which increased by $\uparrow 13.74 \%$ as mean of HARI before intervention was $(0.80 \pm 0.11)$ vs $(0.90 \pm 0.13)$ after intervention $(\mathrm{P}<0.001)$, HAPI increased by $(4.70 \%)$ in $61.3 \%$ of patients with mean $1.71 \pm 0.36$ before interventionvs $1.78 \pm 0.36$ after intervention $(\mathrm{p}=0.03)$, also SARI was significantly increased $(8.01 \%)$ in $80.6 \%$ of patients with mean before intervention $0.77 \pm 0.13$ vs after intervention $0.82 \pm 0.14 \quad(\mathrm{P}<0.001)$, while SAPI showed significant increase $(11.83 \%)$ in $93.5 \%$ of patients with mean \pm SD before intervention $1.57 \pm 0.37$ vs $1.74 \pm 0.36$ after intervention $(\mathrm{P}<0.001)$. Portal vein velocity significantly decreased in $80.6 \%$ of patients $(\mathrm{P}=0.019)$, liver vascular index decreased in $71 \%$ of patients $(\mathrm{P}=0.025)$ and portal hypertensive index significantly increased in $71 \%$ of patients $(\mathbf{P}<0.001)$. (Table 2, Figure 2)
No significant differences was found between the studied groups regarding the size of the esophagealvarices $(\mathrm{P}=0.509)$. Also no significant change was found before and after interventional therapy regarding the size of esophageal varices $(\mathrm{P}=0.405,0.564)$ in TACE group and MWA group respectively.

In our work there was a highly statistical significant difference regarding the baseline liver stiffness between the studied groups $(\mathrm{P}<0.001)$, with a higher value in the TACE group than in the MWA group, where the mean value in the patients who underwent TACE was $45.48 \pm 15.49$ in comparison to those of MWA with mean value $23.48 \pm 8.38$. (Table 3, Figures 1, 2)

Also the patients that showed well ablation of the focal lesions on triphasic CT had a significantly lower base line LSM with mean value $29.04 \pm 13.77$ than those with residual activity with mean $44.36 \pm 17.68$ and new focal lesions with mean value $35.03 \pm 15.69(\mathrm{P}=0.005)$. 


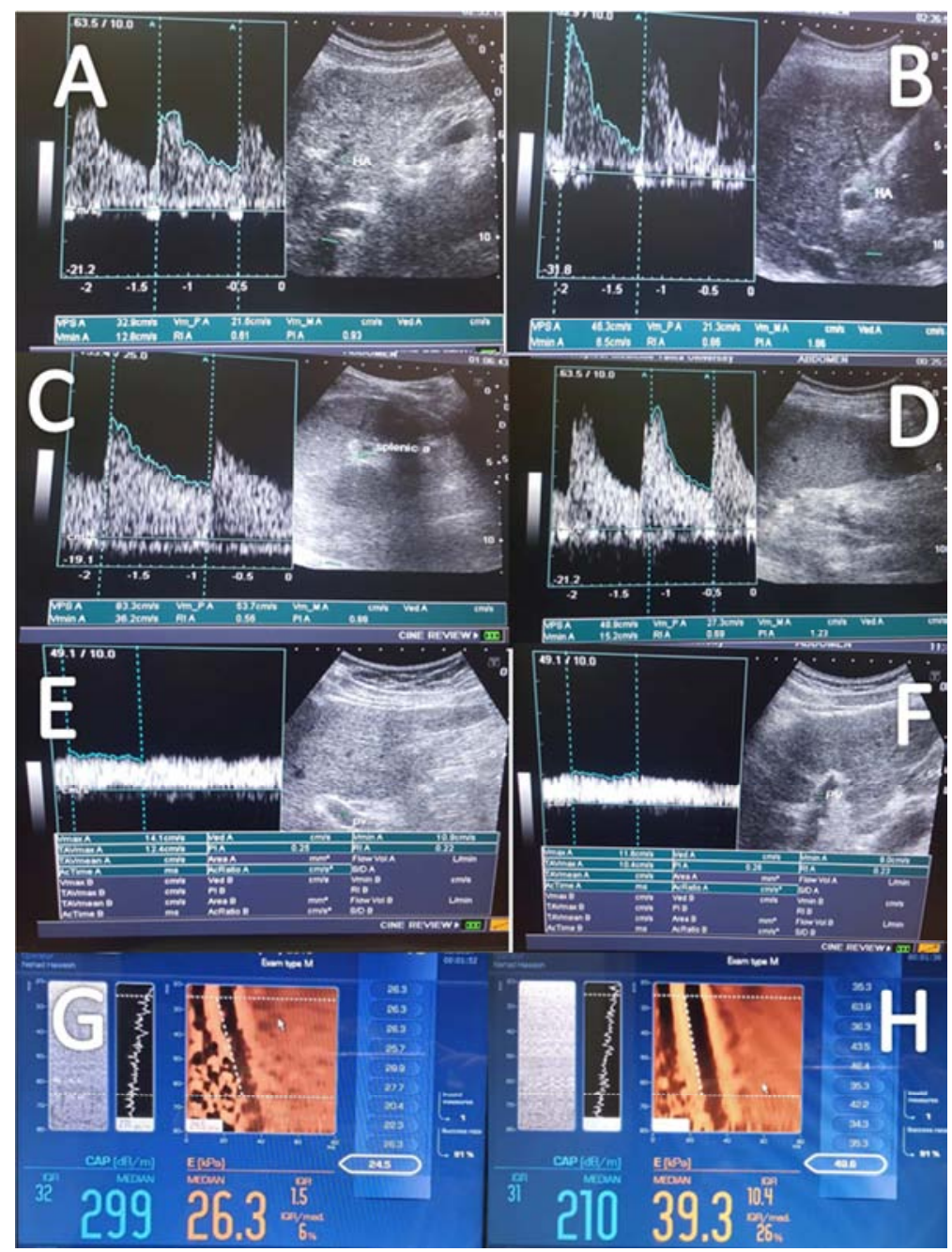

Figure 2. Hepatic artery resistance index, pulsatility index before $(A)$ and after $(B)$ intervention, splenic artery resistance index, pulsitality index before $(C)$ and after $(D)$ intervention, portal vein velocity before $(E)$ and after $(F)$ intervention and liver stiffness measured by fibroscan before $(G)$ and after $(H)$ intervention in 52 years old patient who had TACE as an interventional therapy to HCC and follow up of CT after 6 months of therapy showed well ablation of the focal lesion.

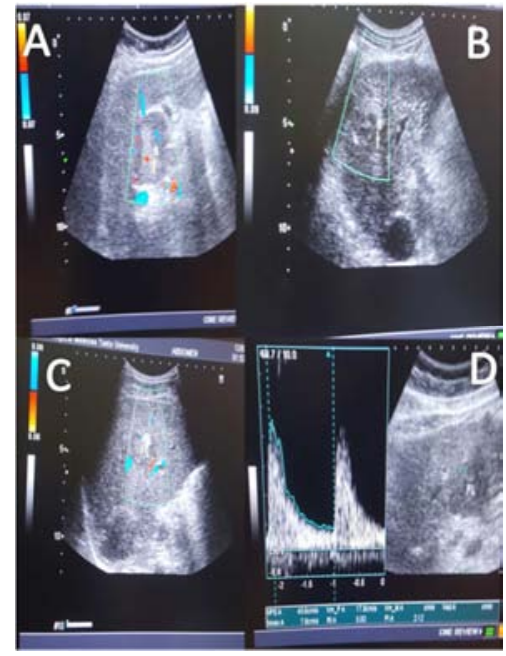

Figure 3. (A) focal lesion by color Doppler ultrasonography showing vascularity (B) showing avascular focal lesion after intervention (C) showing focal lesion with residual activity after intervention (D) showing focal lesion resistance index and pulsitality index by power Doppler.

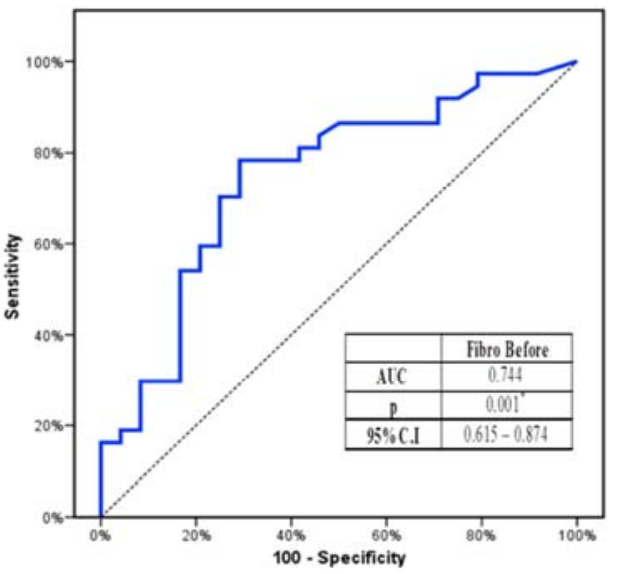

Figure 4. Receiver Operator Characteristic (ROC) curve results for preinterventional liver stiffness cut off value in $\mathrm{kPa}$ to predict well ablation.

In this work we found a highly statistically significant increase in the liver stiffness in patients who had undergone TACE on examination after 6 months of the procedure mean \pm SD before intervention $(45.48 \pm 15.49)$ vs 
(51.47 \pm 15.04$)$ after intervention $(\mathrm{P}<0.001)$ and percent of change of $\uparrow 14.80$ in $93.4 \%$ of patients. Also a statistically significant increase in the livers stiffness in patients who had undergone MWA on examination after 6 months of the procedure with mean \pm SD before intervention (23.48 \pm 8.38 ) vs $(27.38 \pm 9.32)$ after intervention $(\mathrm{P}<0.001)$ and percent of change of $17.52 \%$ in $100 \%$ of patients. (Table 3, Figures 1, 2)

At cut off value $\leq 35.2 \mathrm{kPa}$ liver stiffness measurement had the ability to predict well ablation with sensitivity $78.38 \%$, specificity 70.83\%., PPV 80.6\%, NPV 68.0\%. (Figure 4)

Table 3. Liver stiffness measurement by transient elastography and the prognostic value of base line LSM.

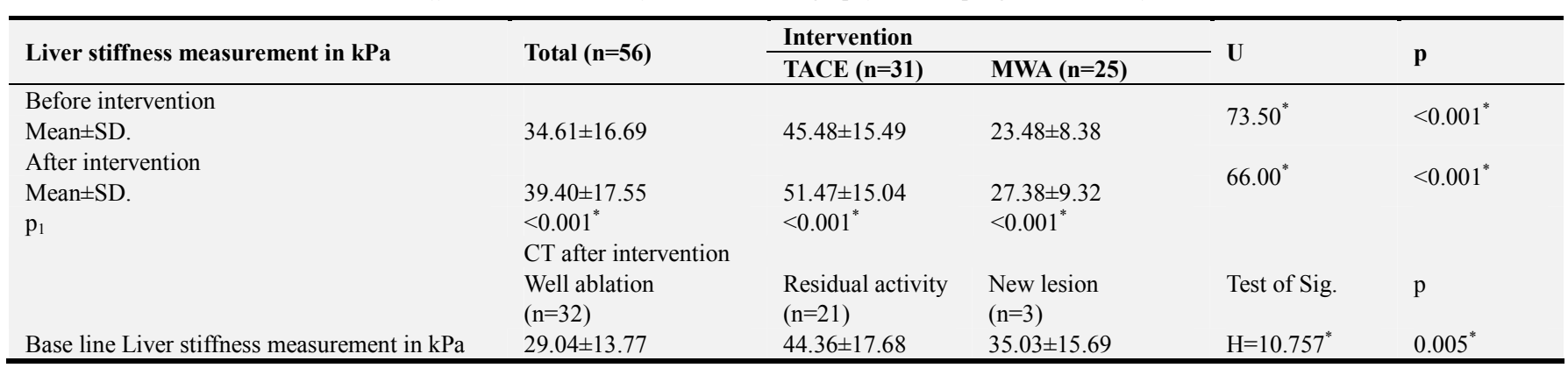

U: Mann Whitney test $\mathrm{H}$ : H for Kruskal Wallis test

$\mathrm{p}$ : $\mathrm{p}$ value for comparing between TACE and MWA

$\mathrm{p}_{1}$ : $\mathrm{p}$ value for Wilcoxon signed ranks test for comparing between before and after intervention

*: Statistically significant at $\mathrm{p} \leq 0.05$

TACE: Transarterial chemoembolisation

RF: Radiofrequency ablation

MWA: Microwave ablation

\section{Discussion}

The aim of this prospective study was to assess the ability of Doppler Ultrasound parameters and liver stiffness assessment using fibroscan to predict and evaluate the effectiveness of TACE and MWA as HCC interventional therapies.

After undergoing HCC intervention therapy $57.4 \%$ of the lesions in the total studied population was found to become avascular. In those who had TACE $51.6 \%$ of the lesions showed post intervention vascularity while in the MWA group $40 \%$ of the lesions still showed vascularity, with statistically significant difference in the color Doppler results before and after intervention in the three groups.

We compared the results of the Doppler ultrasound examination with the results of the triphasic CT after intervention and found that $83.78 \%$ of the well ablated lesions in the triphasic CT showed no vascularity on the Doppler ultrasound examination and $85.7 \%$ of the lesions with residual activity showed color and waveform signals on Doppler ultrasound examination also 2 of 3 cases who were found to develop new lesions on follow up triphasic CT showed positive Doppler ultrasound examination findings of active focal lesion vasculature.

These results are similar to previous studies which proved that power Doppler sonography was significantly successful in showing color signals in the residual portion of the tumors after treatment $[13,14]$. This also agrees with Tanaka, 2020 [14] who stated that power Doppler sonography was nearly equal to $\mathrm{CT}$ in showing tumor vascularity, as the color signals revealed by color or power Doppler sonography corresponded to the enhanced areas that were not ablated seen on CT.
As Doppler ultrasound was proved to be as a reliable and effective method for the evaluation of PHT [15].

So we examined our patients with Doppler ultrasound to assess the effect of TACE and MWA as interventional therapy of HCC on the hepatic vasculature including the portal vein, hepatic artery and splenic artery as it can give us an idea about the prediction of the risk of development of portal hypertension after interventional therapy.

Doppler ultrasound can be used as a non invasive method to evaluate the severity of PHT through measuring parameters like LVI (liver vascular index), the hepatic vein waveform, hepatic artery pulsitality index (HAPI) and the congestion index which are sensitive parameters that can indicate the degree of severity of portal hypertension [17].

Concerning PHT parameters a significant changes were recorded as regard patients in the TACE group. While patients in the MWA group did not show there significant changes except for HAPI and portal vein velocity that both were significantly increased with non-significant decrease in PHTI.

This indicates the safety of the MWA procedure in comparison to TACE regarding the likelihood of causing portal hypertension. Also the degree of oesophageal varices was not affected after the ablation procedure.

The present results agree with those of El Sherbiny et al., 2016 who found no statistically significant changes concerning PHT parameters assessed by Doppler ultrasound in their HCC patients after MWA [16].

Regarding TACE group, a significant increase in HARI, HAPI, and SAPI was noted. However, portal vein velocity significantly decreased as well the liver vascular index while portal hypertensive index showed significant increase.

This can be explained by the severe necro-inflammatory effect of the therapeutic chemical substance used in TACE on 
the blood vessels and adjacent tissues lead to vascular obliteration, increased tissue resistance, and finally PHT [18].

Similar to our results an increase in PHT indices following ablation procedures was proven in previous studies [19-21].

The other wing of our study was to define the role of transient elastography in defining the effect of different modalities of HCC interventional therapy on liver stiffness and whether the base line liver stiffness had a relation to the response to therapy.

First of all in the TACE group the value of the LSM before intervention was statistically significant higher than in the MWA group.

This difference in the base line liver stiffness can be explained by the fact that the patients that were chosen to undergo TACE usually had larger tumors that are associated with increased production of profibrotic mediators and therefore increased fibrosis [22].

In addition there was a statistically significant increase in the liver stiffness in patients who had undergone TACE after 6 months of the procedure.

The increase in the LSM after TACE procedure can be attributed to the fact that TACE causes hypoxia that increases the expression of certain substances including hypoxiainducible factor- $1 \alpha$, vascular endothelial growth factor, and transforming growth factor- $\beta 1$, these substances aggrevates the fibrosis in the area surrounding the tumor tissue $[23,24]$. Also the liver tissue is affected by the drug agents reaching the portal circulation specially in the area surrounding the tumor [22].

In our study we also found that there was a statistically significant increase in the liver stiffness in patients who had undergone MWA on examination after 6 months of the procedure.

In the MWA group The increase in liver stiffness can be explained by the fact that coagulation necrosis is induced by thermal ablation causing increase in the stiffness of the liver. Further more high temperature generated by the MWA procedure causes loss of fluid from the liver tissue, damage the tissue protein and causes collagen contraction and therefore tissue contraction [25].

In our study we also tried to put a spot light on the relation between the baseline of liver stiffness measurement and the outcome of HCC intervention by correlating the base line liver stiffness with the follow up triphasic CT findings.

A statistically significant difference was found between patients who achieved well ablation, those who had residual activity and those who developed new lesions regarding the baseline liver stiffness measurements.

As LSM before intervention was found to be lower in those patients who achieved complete ablation than those who didn't achieve that (had residual activity and new lesions). Thus, the prediction of well ablation can be predicted by lower LSM before intervention.

This idea is also apparent on investigating each studied group individually, especially in TACE group.

In the present work we set a cut off value $\leq 35.2 \mathrm{KPa}$ at which livers stiffness measurement has the ability to predict good ablation after intervention.

Other cut off values were found in other studies and it may show variation between studies due to different aetiological background, different treatment modalities and patient selection, more than 31.2 predicted recurrence in Lee et al., 2017 [11]. Wong et al., 2013 [24] who found that HCC patients with pretreatment LSM values more than $13-13.4 \mathrm{kPa}$ experienced a higher recurrence. Also Qi et al., 2017 [26] found the best cut-off value of LSM for HCC by ROC analysis that had good outcome was 13.2 $\mathrm{kPa}$.

Limitation of the study is limited sample size so more studies on larger cohort is needed to evaluate the opportunity to modify the current recommendations in follow up of HCC after intervention and, at the same time, reduce costs. Also long follow up period can enforce the present results.

\section{Conclusion}

TACE is associated with increased portal hypertension indices than MWA and Doppler parameters is a non-invasive simple technique that can be used for follow up of HCC patients after interventional therapy. Also liver stiffness measurement can be used as a good predictor of good ablation of HCC.

\section{Conflicts of Interest}

All the authors do not have any possible conflicts of interest.

\section{References}

[1] Torre LA, Bray F, Siegel RL, Ferlay J, Lortet-Tieulent J, Jemal A. (2015) Global cancer statistics, 2012. CA: a cancer journal for clinicians 65: 87-108.

[2] Rashed WM, Kandeil MAM, Mahmoud MO, Ezzat S. (2020) Hepatocellular Carcinoma (HCC) in Egypt: A comprehensive overview. Journal of the Egyptian National Cancer Institute 32: 1-11.

[3] Ho SY, Liu PH, Hsu CY, Hsia CY, Lee YH, Lee RC, et al. (2017) Prognostic role of noninvasive liver reserve markers in patients with hepatocellular carcinoma undergoing transarterial chemoembolization. PloS one 12: e0180408.

[4] Bruix J, Gores GJ and Mazzaferro V. (2014) Hepatocellular carcinoma: clinical frontiers and perspectives. Gut 63: 844-855.

[5] Govaere $\mathrm{O}$ and Roskams T. (2015) Pathogenesis and prognosis of hepatocellular carcinoma at the cellular and molecular levels. Clin Liver Dis; 19 (2): 261-276.

[6] Lencioni R, Menu Y and Bartolozzi C. (2012) Ultrasound and Doppler Ultrasound of Hepatocellular Carcinoma In Liver Malignancies: Diagnostic Imaging and Radiation Oncology. Springer-verlag mailand publisher; 5: 108-188.

[7] Padhya KT, Marrero JA and Singal AG. (2013) Recent advances in the treatment of hepatocellular carcinoma. Current opinion in gastroenterology 29: 285-292. 
[8] Anaye A, Perrenoud G, Rognin N, Arditi M, Mercier L, Frinking P, et al. (2011) Differentiation of focal liver lesions: usefulness of parametric imaging with contrast-enhanced US. Radiology 261: 300-310.

[9] Kim Y, Rhim H, Cho OK, Koh BH, Kim Y. (2006) Intrahepatic recurrence after percutaneous radiofrequency ablation of hepatocellular carcinoma: analysis of the pattern and risk factors. European journal of radiology 59: 432-441.

[10] Bedossa P, Dargère D and Paradis V. (2003) Sampling variability of liver fibrosis in chronic hepatitis C. Hepatology 38: 1449-1457.

[11] Lee YR, Park SY, Kim SU, Jang SY, Tak WY, Kweon YO, et al. (2017) Using transient elastography to predict hepatocellular carcinoma recurrence after radiofrequency ablation. Journal of gastroenterology and hepatology 32: 1079-1086.

[12] Scheinfeld MH, Bilali A and Koenigsberg M. (2009) Understanding the spectral Doppler waveform of the hepatic veins in health and disease. Radiographics 29: 2081-2098.

[13] Yang F, Zhao J, Liu C, Mao Y, Mu J, Wei X, et al. (2019) Superb microvascular imaging technique in depicting vascularity in focal liver lesions: more hypervascular supply patterns were depicted in hepatocellular carcinoma. Cancer Imaging 19: 92.

[14] Koito K, Namieno T, Ichimura T, Hirokawa N, Syonai T, Hareyama M, et al. (2000) Power Doppler sonography: evaluation of hepatocellular carcinoma after treatment with transarterial embolization or percutaneous ethanol injection therapy. American Journal of Roentgenology 174: 337-341.

[15] Tanaka H. (2020) Current role of ultrasound in the diagnosis of hepatocellular carcinoma. Journal of Medical Ultrasonics: $1-17$.

[16] El Sherbiny W, Abdel Rahman A, Diasty M, Shaltout SW. (2016) Changes in Doppler parameters of portal pressure after interventional management of hepatocellular carcinoma. Abdominal Radiology 41: 1532-1538.

[17] Baik SK, Kim JW, Kim HS, Kwon SO, Kim YJ, Park JW, et al. (2006) Recent variceal bleeding: Doppler US hepatic vein waveform in assessment of severity of portal hypertension and vasoactive drug response. Radiology 240: 574-580.
[18] Zhang L, Duan YY, Li JM, Yin JK. (2007) Hemodynamic features of Doppler ultrasonography in patients with portal hypertension: intraoperative direct measurement of portal pressure in the portal venous system. J Ultrasound Med 26: 1689-1696.

[19] Raoul J-L, Forner A, Bolondi L, Cheung TT, Kloeckner R, de Baere T. (2019) Updated use of TACE for hepatocellular carcinoma treatment: How and when to use it based on clinical evidence. Cancer treatment reviews 72: 28-36.

[20] Sieghart W, Hucke F, Pinter M, Graziadei I, Vogel W, Müller C, et al. (2013) The ART of decision making: retreatment with transarterial chemoembolization in patients with hepatocellular carcinoma. Hepatology 57: 2261-2273.

[21] Scheiner B, Ulbrich G, Mandorfer M, Reiberger T, Müller C, Waneck F, et al. (2019) Short-and long-term effects of transarterial chemo-embolization on portal hypertension in patients with hepatocellular carcinoma. United European gastroenterology journal 7: 850-858.

[22] Abdelaziz AO, Abdelhalim H, Elsharkawy A, Shousha HI, Abdelmaksoud AH, Soliman ZA, et al. (2019) Liver stiffness measurement changes following hepatocellular carcinoma treatment with percutaneous microwave ablation or transarterial chemoembolization: a cohort study. European journal of gastroenterology \& hepatology 31: 685-691.

[23] Qu K, Yan Z, Wu Y, Chen Y, Qu P, Xu X, et al. (2015) Transarterial chemoembolization aggravated peritumoral fibrosis via hypoxia-inducible factor- $1 \alpha$ dependent pathway in hepatocellular carcinoma. Journal of gastroenterology and hepatology 30: 925-932.

[24] Wang Y, Xiong B, Liang B, Zhao H, Li H, Qian J, et al. (2013) Hepatic parenchymal changes following transcatheter embolization and chemoembolization in a rabbit tumor model. PloS one 8: e70757.

[25] Velez E, Goldberg SN, Kumar G, Wang Y, Gourevitch S, Sosna J, et al. (2016) Hepatic thermal ablation: effect of device and heating parameters on local tissue reactions and distant tumor growth. Radiology 281: 782-792.

[26] Qi M, Chen Y, Zhang G-Q, Meng Y-J, Zhao F-L, Wang J, et al. (2017) Clinical significance of preoperative liver stiffness measurements in primary HBV-positive hepatocellular carcinoma. Future Oncology 13: 2799-2810. 